\title{
The Challenge of Including Chemodiversity, and the Potential Economic Use of New Natural Compounds and Processes, in the BIOTA/FAPESP Program
}

Biological diversity, or biodiversity, is the term used to define the variety of life on Earth. It is the combination of life forms and their interactions with one another, and with the physical environment that has made Earth habitable for humans. Throughout the evolutionary process of the planet ecosystems, underpinned by biodiversity, provided the basic necessities for life in Earth. For mankind this support, currently named ecosystem services, provided and continue to provide from food production through pollination to soil stability, which reduces the possibility of landslides, as well as cultural and spiritual services. Thus, the loss of biodiversity constitutes a critical problem for the future of the Earth and for humankind. Therefore all kind of investments towards biodiversity science is amply recognized as a priority, and a flourishing area of scientific research in both the developed and developing countries.

Concern over the loss of biodiversity and the recognition of its important role in supporting human life motivated the conception of the Convention on Biological Diversity/CBD, ${ }^{1}$ approved in the Rio 92 meeting, and more recently of the Intergovernmental Platform on Biodiversity and Ecosystem Services/IPBES. ${ }^{2}$ The Convention is based in three similarly important and complementary pillars: the conservation of biodiversity, the sustainable use of its components, and the fair and equitable sharing of benefits resulting of the utilization of these components. While the mission of IPBES is to strengthen the science-policy interface for biodiversity and ecosystem services for the conservation and sustainable use of biodiversity, long-term human well-being and sustainable development.

Based on the importance of biodiversity conservation for the future of the Earth, in April 1996, a group of approximately 100 State of São Paulo researchers discussed, under the umbrella of the State of São Paulo Research Foundation/FAPESP,${ }^{3}$ the possibility of organizing a special research project focusing on Conservation and Sustainable Use of Biodiversity. In March 1999, three years later, FAPESP launched the BIOTA/FAPESP Program: The Virtual Institute of Biodiversity. ${ }^{4} \mathrm{~A}$ ten years research program encompassing also the study of the secondary metabolites or chemodiversity associated to biodiversity, that constitutes one of the most important factory of molecules. These molecules are not only essential to the protection of the organisms that produces them, but are a strategic source of inspiration for the development of new drugs, cosmetics, food or plague control.

This program aimed not only at discovering, mapping and analyzing the origins, diversity and distribution of the flora, fauna and microorganisms of the State of São Paulo, but also at evaluating the possibilities of sustainable exploitation of plants and other organisms with economic potential, and assisting in the formulation of conservation and sustainable use policies of a very rich (more than 7,500 species of higher plants, 230 of mammals, 750 of birds, 500 of reptile and amphibians, 400 of fresh water fishes and 600 of marine fishes) biodiversity of São Paulo State.

Among the initial Thematic Projects approved within the BIOTA/FAPESP Program only one "Conservation and Sustainable Use of the Diversity from Cerrado and Atlantic Forest: Chemical Diversity and Prospecting for Potential Drugs” (Proc. Fapesp 98/05074-0) had focus on the chemodiversity, looking for biologically active natural products from Atlantic and Cerrado plant species. Based on the good results of this project and a discussion with researchers of the area of bioprospection, in 2002 the Program started a new venture aiming to stimulate and support the search for natural bioactive products of potential economic value, as one of the means to promote the sustainable use of the state's biodiversity. This new initiative was named BIOprospec TA. 5

In 2009-2010 the Steering Committee of the BIOTA/ FAPESP Program organized a three day meeting, with researchers linked to the Program, to produce a critical evaluation and propose a research plan for the following 10 years. Organizing the ideas produced by this meeting together with the previous external evaluations of the Program the Steering Committee produced the "BIOTA/ FAPESP Science Plan \& Strategies for the next decade", 6 
which was approved by FAPESP granting Research Program on Biodiversity Characterization, Conservation, Restoration and Sustainable Use support until 2020.

The major and most important program dedicated to biodiversity research in the American Continent celebrates 15 years, having supported more than 50 projects within the BIOprospecTA, revealing that the biodiversity of the São Paulo State is a rich source of new compounds of economic importance.

Historically, natural products from land, sea and fresh water, as plants, microorganisms, insects and other animals, were the source of virtually all pharmaceutical formulations. More recently, natural products have continued to inspire medicinal chemistry, introducing several natural products derivatives in clinical trials or providing leads for compounds that have entered clinical trials, especially as anticancer and antimicrobial agents.

Brazil has the greatest biological diversity of the world, which is a wealth of molecular diversity out there, waiting to be discovered and utilized. The BIOTA/ FAPESP Program, through BIOprospecTA, will continue to stimulate and support projects in this promising area of research.

Carlos A. Joly

IB-UNICAMP

Coordinator of the BIOTA/FAPESP Program

Vanderlan S. Bolzani

IQ-UNESP

BIOTA/FAPESP Program Steering Committee

\section{References}

1. http://www.cbd.int, accessed in December 2016.

2. http://www.ipbes.net, accessed in December 2016.

3. http://www.fapesp.br, accessed in December 2016.

4. http://www.biota.org.br, accessed in December 2016.

5. http://www.bioprospecta.org.br, accessed in December 2016.

6. http://www.fapesp.br/biota/10scienceplan.pdf, accessed in December 2016. 